\title{
Review on Treatment Methods for Heterogeneity of External Data in Operational Risk Measurement
}

\author{
Kun Song ${ }^{1, a}$, Xiaoqian Liu $^{2, b}$ \\ ${ }^{1}$ College of Economics, Sichuan Agricultural University, Chengdu 611130, China \\ ${ }^{\mathrm{a}}$ email, ${ }^{\mathrm{b}}$ email
}

Keywords: Operational Risk, Measurement, External Data, Heterogeneity

\begin{abstract}
With implement the bottom-up approach to measure operational risk of commercial banks, external loss data must be incorporated to supplement insufficient of internal loss data. But the main limitation of utilizing external data is the apparent heterogeneity in the data. To improve the accuracy of measurement results, it's necessary to find out optimal ways to pool internal and external data. This paper reviews literatures regarding the methods to deal with the external data, and puts forward problems for further research: data collection standard into the database, incorporation standard of external data, and how to combined scenario analysis and business environment and internal control factors
\end{abstract}

\section{Introduction}

Faced with the rapidly changing external environment and the increasingly fierce industry competition, commercial banks inevitably face increasingly complex challenges, operational risk is a major risk. For risk management, it is usually required to identify, measure, monitor, and control of these processes slow release. This process demonstrates a measure of risk is the prerequisite and basis for managing risk, so if skipped measure of risk management and direct talk, there are suspected of putting the cart before. Therefore, the accuracy of the relationship between the operational risk measurements of the effectiveness of operational risk management, measurement is one of the core issues that must be addressed.

Although the current domestic and foreign scholars are on research techniques and methods of operational risk measurement are the Hundred Flowers, but these studies need to build an effective historical loss data sufficient basis. Given the high operational risk loss of the low-frequency characteristics, as well as for the maintenance of their own image bank needs reluctant to publish part of the risk loss events operational risk loss data is generally difficult to collect and relatively scarce, and therefore integrate external data to supplement the sample is very Necessary. But the prevalence of external loss data heterogeneity, and now on how to import external data when it is processed to weaken discuss heterogeneity of approach to the late start, the literature is not much. This article comments on the current situation to study the issue and propose future research directions in order to bring the sample by reducing the external bias to improve the operation of the scientific accuracy of risk measurement and management.

\section{The Bottom-up Model of Historical Loss Data Requirements}

In general, the operational risk measurement method is divided into two kinds of top-down and bottom-up. Among them, the top-down model is the main financial indicators and earnings volatility of the variable to measure risk. Although the characteristics of these methods is easy to collect data and the calculation is simple, but many scholars expressed their full measure results questioned, they want to focus on two points: First, the revenue targets and the lack of adequate operational risk correlation, the second is too simple and high measurement results obtained venture capital, does not apply to the size of medium-sized commercial banks. Bottom-up model mainly on the basis of historical loss data of operational risk and commercial banking business line analysis, the difference between the risk loss event type or types of business products gradually measure risk. While the bottom-up model is highly sensitive to risk, but its application is a prerequisite for the 
availability and integrity of historical loss data, so the higher the loss of data quality and quantity requirements. Haubenstock and Hardin considered that when the number of loss events is greater than 100, and includes a very large loss of data (tail), can then be modeled directly on the risk, the greater the amount of data used by the more stable measurement results. After all significantly affect the smooth and the results of the amount of data would be insufficient data. Basel II also requires, if used to calculate the operational risk operational risk advanced measurement method, the loss of at least 5 years of observation data, if the initial use of advanced measurement methods, must have three years of loss data.

Commercial sources of operational risk loss data is nothing less than three points: occurred in the Bank's internal loss data, external loss data occurs in other banks, as well as scenario analysis data. Given the commercial banks operational risk loss data as well as the reality of a serious shortage of external loss data correlation, scholars at the operational risk measurement requires the introduction of external loss data, because only internal loss data can not accurately estimate the tail of the distribution of operational risk. New Basel Capital Accord Section 674 paragraph also states: "If any reason to suppose commercial banks are facing a high risk of potential loss of low frequency of exposure of commercial banks operational risk measurement system must use public data and industry mixed data (including external data)." Here's how to integrate research for internal and external loss data were reviewed.

\section{External Loss Data Processing Research}

Currently on view supplemental data loss method is divided into two categories, scholars believe that the commercial banks in this industry, external loss data and internal loss data has some relevance, it is simply the external loss data incorporated internal loss data to measure the industry's operational risk capital requirements. Another scholar within the external loss data is simply combined use of such data processing method expressed doubts that external data applicability and relevance are still worth exploring, the reliability of this approach is not high. After all, different banks assets, product lines, business processes, risk appetite and risk control system, there is a difference, even if the same industry, the loss of data each commercial bank is subject to different distribution of sample data heterogeneity. Consequently, simply mixing internal and external data practices more far-fetched, will change the distribution of the original data, the mathematical model on the basis of the establishment of the measure will reduce the accuracy of the results. It needs for external loss data heterogeneity processing. Alexander proposes three directions: First, the internal and external loss data modeling, and then be merged after each method; the second is the internal and external loss data into the same dimension and then to measure; the third is in external loss data than the critical value integrated into the model for internal loss data inside. Of course, there are other scholars to adjust their thinking, the following were to be reviewed and commented on the relevant research literature.

Credibility Theory of Bühlmann-Straub credibility model is similar to insurance through the rational use of data loss over the same period of the recent loss of Portfolio and subjective selection of data to estimate pretest and post premiums. Therefore, the amount of operational risk loss of individual commercial banks next year completely to the letter of the factor weights to infer assessed based on historical loss data and other lines of the Bank. Dominik et al. (2007) that the credibility theory to be able to take care of the lack of data loss situation, you can respectively internal and external loss data modeling, and then using Bayesian credibility theory and method processing model. Lu Jing and Guo Lei (2012) of the sample data is divided into seven groups, and then were to give credibility factor $\mathrm{z}$ and VaR value of each group, and finally get through operational risk Extreme credibility model processing: $\quad z \times V a R_{\text {internal loss data }}+(1-z) \times V a R_{\text {External loss data }}$. But in fact, operational risk loss mathematical characteristics of commercial banks are the existence of differences, so the result is debatable.

Of course, also after the introduction of the credibility theory to external data processing, 
combined with internal data to measure operational risk, this method can ensure that the database after the merger to produce unbiased estimation (Frachot and Roncalli, 2002). While this provides a good idea of how to solve the problem of a lack of operational risk data, but more research in theory, has not been implemented.

Some scholars use as a threshold to determine whether an external loss data into the standard measurement sample. Think may be mixed with the Bank's internal loss data loss distribution of the same data from other banks (external data must be greater than the threshold), the loss of intensity distribution can be qualified by the external loss data and internal loss data are mixed to form (Baud, Frachot and Roncalli, 2002). But this method has a higher precision threshold requirement and the author did not give a specific threshold selection method.

Some scholars have proposed the establishment of the loss of strength and loss frequency conversion model of thinking. For the loss of intensity distribution, Hartung (2004) established the loss of strength transfer model:

$$
\operatorname{Loss}_{\text {external }}=\operatorname{Loss}_{\text {internal }}\left\{1+\alpha\left[\left(\frac{\operatorname{Scal}\left(\text { Loss }_{\text {external }}\right)}{\left.{\text { Scal }\left(\text { Loss }_{\text {internal }}\right)}\right)}\right)^{\beta}-1\right]\right\}
$$

Loss $_{\text {external }}$ is the to be adjusted external loss, Scal(Loss $\left.{ }_{\text {external }}\right)$ data for the parameters to be adjusted ratio of banks, Scal $\left(\right.$ Loss $\left._{\text {internal }}\right)$ is the Bank of the scale parameter. If further subdivided, operational risk loss events can be classified into two parts: general loss (shared by banks, such as changes in macro-economic, political and cultural) and special damages (all individual banks, such as a specific line of business or product line), so it is possible to establish the loss of strength of inter-agency transition model: $\operatorname{loss}_{y}=g(\text { partial })_{y} \times \operatorname{loss}_{x} / g(\text { partial })_{x}(\mathrm{Na}, 2006)$.

Some scholars believe may be related to the relative method (relative related approach is to use operational risk events disclosed a method to estimate the distribution of its losses on the lack of sufficient data, the risk of type) to filter external data (Reynold and David, 2003), is compared with the control of the Bank's operations and wind the smallest difference other commercial banks external data included in the sample.

\section{Conclusion}

Current commercial banks operational risk loss database construction is not perfect, in a single commercial bank internal loss data-poor situation, when operational risk measurement integrate external loss data to supplement internal loss data is necessary and required. This paper reviews the existing literature, found on how to deal with external data to reduce the heterogeneity of the impact of the issues raised relatively late, so little research and treatment methods have considerable differences, study results and practical application there is a certain gap. However, with domestic and foreign industry to improve operational risk measurement precision requirements of domestic and foreign scholars we have realized the importance of this issue. To study literature review, in addition to considering how to enhance the operability of treatment, but also the future to measure the loss from the building database, integrated standard external loss data and scenario analysis combined with other aspects.

\section{References}

[1] Pezier J. A Constructive Review of Basel's Proposals on Operational Risk[M]. SMA Discussion Paper in Finance 2002-20, FT- Prentice Hall, 2004.

[2] Haubenstock M. and Hardin L. Loss Distribution Approach, Operational Risk[M]. Pearson Education Limited, 2003.

[3] Embrechts P., Furrer H., Kaufmann R.. Quantifying Regulatory Capital for Operational Risk[J]. Derivatives Use, Trading \& Regulation, 2003, 9(3): 217-233.

[4] Nash R.A. Three Pillars of Operational Risk [M]. In Operational Risk: Regulation, Analysis 
and Management. London: Prentice-Hall-Financial Times, 2003.

[5] Alexander Carol. Operational Risk: Regulation, Analysis and Management[M]. Financial Times Prentice Hall, 2003.

[6] Dominik D. Lambrigger, Pavel V. Shevchenko, Mario V. Wüthrich. The Quantication of Operational Risk Using Internal Data, Relevant External Data and Expert Opinion[J]. Journal of Operational Risk, 2007, 2(3): 3-27.

[7] Lu Jing, Guo Lei commercial banks operational risk measurement research - Extreme Value Theory and the reliability factor model [J]. Shanxi University of Finance and Economics, 2012 (9): 45-57.

[8] Hartung, T. Operational Risks: Modeling and Quantifying the Impact of Insurance Solutions[Z]. Working Paper, Institute of Risk Management and Insurance Industry, Ludwig Maximilians University Munich, Germany, 2004

[9] Na H.S., J. Van Den Berg, L.C. Miranda, M. Leipoldt. An Econometric Model to Scale Operational Losses[J]. Operational Risk, 2006, 1(2):11-31. 